\title{
Reuven AMITAI, The Mongols in the Islamic Lands, Studies in the History of the Ilkhanate
}

Ashgate, Variorum Collected Studies Series, 2007, 372 p.

\section{Alaa Talbi}

\section{CpenEdition}

\section{Journals}

Édition électronique

URL : http://journals.openedition.org/beo/86

DOI : $10.4000 /$ beo.86

ISBN : 978-2-35159-316-5

ISSN : 2077-4079

\section{Éditeur}

Presses de l'Institut français du Proche-Orient

\section{Édition imprimée}

Date de publication : 1 septembre 2009

Pagination : 405-407

ISBN : 978-2-35159-143-7

ISSN : 0253-1623

\section{Référence électronique}

Alaa Talbi, «Reuven AmItal, The Mongols in the Islamic Lands, Studies in the History of the Ilkhanate», Bulletin d'études orientales [En ligne], Tome LVIII | Septembre 2009, mis en ligne le 28 septembre 2009, consulté le 22 septembre 2020. URL : http://journals.openedition.org/beo/86 ; DOI : https://doi.org/ $10.4000 /$ beo.86 
THE MONGOLS IN THE ISLAMIC LANDS, STUDIES IN THE HISTORY OF THE ILKHANATE,

Reuven AMITAI

Ashgate, Variorum Collected Studies Series, 2007, $372 \mathrm{p}$.

[ISBN : 978-0-7546-5914-3]

Cet ouvrage, divisé en trois grandes parties, regroupe un ensemble d'articles publiés par R. Amitai (professeur à l'université hébraiqque de Jérusalem) qui sont consacrés à l'étude des relations entre les Ilkhanides et les Mamelouks de 658/1260 à 723/1323. Cette période, caractérisée par des affrontements militaires et des tentatives de rapprochement, aboutit enfin à la réconciliation juste avant l'effondrement de l'Ilkhanat persan.

Dans la première partie (Institutions et Historiographie), R. Amitai expose l'historique du titre «I İhān » en démontrant qu'il n'existe aucune preuve dans les sources qui atteste des circonstances dans lesquelles ce titre fut adopté. Par contre, il confirme qu'à partir de 657/1259 cette titulature apparaît sur les monnaies. Dans un second article, il décrit le fonctionnement du système de l'iqta $\vec{a}$ dans le milieu nomade türko-mongol. En partant d'un constat, la dissemblance entre les administrations seldjoukide et mongole (bien qu'elles soient issues de tenants du pouvoir d'un milieu nomade proche), les pratiques en la matière s'exercent de manière très différentes.

L'A. montre également l'utilité et la richesse des sources mameloukes pour tenter de comprendre la situation dans le camp "adverse ", en d'autres termes les Ilkhanides. Il s'appuie en particulier sur al-Nuwayrī (m. 733/1333), un auteur bien informé sur les Mongols. R. Amitai lui reconnaît une vision des Mongols qui lui est propre et qui est un peu différente de celle de la classe mamelouke dirigeante (Baybars al-Manșūrī, m. 725/1325, par exemple). Ainsi, ildépouilleles biographies de Rašīd al-Dīn, présentées et annotées par les chroniqueurs mamelouks, qui fournissent beaucoup d'informations sur son cursus intellectuel et sa carrière politique. Par ailleurs, les sources mameloukes sont les seules à témoigner de son rôle dans l'attaque mongole de la Syrie par Ġāzān (r. 695-704/1295-1304). Les sources mameloukes apportent un éclairage différent des sources persanes qui souvent sont moins précises et plus partiales. À travers ce bref aperçu 
historiographique, on peut constater que les informations circulaient en dépit du contexte conflictuel.

Dans la deuxième partie du volume (Conversion des Mongols à l'islam), R. Amitai suit la genèse, l'évolution et le "caractère" qui ont marqué cette " islamisation». Le premier ilkhan à se convertir fut Ahmad Tegüder (r.680683/1284-1282) poussé par une conviction personnelle et la personnalité de certains soufis. Mais il a échoué à imposer l'islam comme religion officielle de l'État, un échec qu'il paya de sa vie. En 695/1295, la conversion de Ġāzān constitua un événement très important pour la classe dirigeante mongole et les sujets de l'Ilkhanat persan. L'auteur présente les deux aspects de la conversion, de Ġāzān. En premier lieu, il met l'accent sur l'aspect politique de cette conversion à savoir la mobilisation de ses sujets musulmans pour le soutenir dans sa lutte contre son rival, Baidu. Ġāzān voulait également consolider son indépendance vis-à-vis du grand khan mongol. En second lieu, il souligne l'aspect «syncrétique » de cette conversion puisque Ġāzān continua à maintenir plusieurs coutumes et traditions mongoles. Un islam contesté et même rejeté par les théologiens musulmans, comme Ibn Taymiyya (m. 728/1328) par exemple. R. Amitai tente de déceler les acteurs de l'islamisation des Ilkhanides. Il partage l'idée du rôle actif des soufis dans l'islamisation des tribus türkes en Asie: Seldjoukides et autres. On trouve quelques attestations du rôle des soufis dans le processus d'islamisation des Mongols dans la poésie arabe de l'époque mamelouke qui, par exemple, considère Ġāzān comme un faqìr. Par contre, l'auteur nie un autre facteur: celui de la similitude entre les soufis et les chamanes qui auraient poussé l'élite mongole à se convertir. Les soufis ont constitué une partie de l'entourage des Ilkhans, mais il y avait d'autres « hommes de religion » et des théologiens chiites.

La troisième partie (Guerres ilkhanomameloukes) est consacrée à l'étude des conflits qui opposèrent les Mongols et les Mamelouks entre 658/1260 (date de la bataille de 'Ayn Ǧālūt) et 723/1323 (date de la signature d'un traité de paix). Ce traité fut négocié par un marchand d'esclaves, un certain Mağd al-Sallāmī (on notera au passage le rôle important joué par les marchands tant du côté ilkhanide que mamelouk). R. Amitai fait remarquer que les sources persanes sont quasi muettes sur la signature de ce traité. Il étudie les raids mongols et la notion de «frontières » entre les deux États rivaux. Il effectue une comparaison entre le raid sur la Palestine de 658/1260 et celui qui eut lieu en 699/1300, au cours duquel les forces mongoles n'ont pas rencontré d'opposition sérieuse. Mais il existe une divergence entre les deux événements : la Palestine, qui était le champ de bataille en $658 / 1260$, passa de nouveau sous contrôle mamelouk en 699/1300, sans bataille. L'A. en conclut que cette région n'était pas la cible directe des Ilkhanides.

R. Amitai s'intéresse ensuite aux combats sur le front nord de la Syrie c'est-à-dire tout le long de l'Euphrate. Les Mamelouks avaient développé une stratégie (militaire, espionnage) afin de contrôler les régions frontalières. Ces frontières «militaires» ont donné naissance aux frontières "politiques » résultant avant tout des données géographiques: un fleuve, l'Euphrate. Pourtant, de part et 
d'autre de ces frontières, il existait une parenté ethnique et linguistique puisque Mamelouks et Mongols étaient issus des steppes eurasiennes. Un facteur qui n'a pas empêché le développement d'une guerre idéologique sans merci entre les deux États.

R. Amitai s'attache également à étudier minutieusement deux exemples de batailles, un choix qui n'est pas arbitraire puisque le vainqueur n'est pas le même dans les deux cas: victoire mamelouke, en $658 / 1260$, sur le commandant en chef de Hülegü, victoire mongole, en 699/1300, concrétisée par la prise de Damas. Il nous propose une lecture "révisée " des sources grâce à un regard sur le terrain et les données topographiques. Cette approche lui permet de reconstituer le déroulement de la bataille de 'Ayn Ǧālūt et d'en confirmer les résultats : un gain de prestige et de légitimité pour les sultans mamelouks. À propos de la campagne de Ġāzān sur Bilād al-Šām en 699/1300, l'auteur s'emploie à reconstituer le déroulement des événements d'une manière souple et motivante basée sur la confrontation des sources mameloukes, syriaques et persanes. Il tente de clarifier les motifs qui ont poussé Ġāzān à se retirer du Bilād al-šām malgré l'écrasante victoire mongole. Des problèmes de logistique (la chaleur, selon Rašīd al-Dīn) pourraient expliquer ce retrait, mais il devait surtout faire face à une invasion du territoire ilkhanide oriental des Chaghataïdes.

R. Amitai s'est également intéressé aux relations diplomatiques et, en particulier, à l'échange épistolaire entre Abāqa (r. 663-680/1265-1281) et Baybars (r. 658675/1260-1277) qui eut lieu en 667/12681269. L'Ilkhan propose la paix, "șulh », ce qui en réalité correspond à une demande de soumission inconditionnelle. Dans un autre article, l'auteur explique qu'Abāqa a tenté de s'allier avec l'Occident latin contre les Mamelouks d'Égypte. L'Ilkhan a profité du contexte des Croisades et a envoyé ses ambassadeurs au roi Édouard

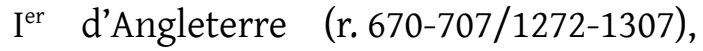
ambassade restée sans suite. Le dernier article de ce volume est consacré au traité de paix signé entre Mamelouks et Ilkhanides en 723/1323 mettant ainsi fin à soixante ans de conflits. L'A. s'interroge, à partir des résultats directs de ce traité de paix, sur l'avenir de ces deux États. Il constate que le sultanat mamelouk parvint à se maintenir plus de deux cents ans alors que l'on assiste par contre à l'effondrement de l'Ilkhanat de Perse en $735 / 1335$, une décennie seulement après la signature du traité.

Alaa TALBI

Doctorant àl'universitéde Manouba(Tunis)/ École pratique des hautes études (Paris) 